ISSN 1991-

Website: http://jsci.utq.edu.iq

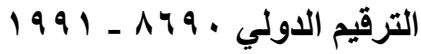

oxnn

Email: utjsci@utq.edu.iq

\title{
Meloxiam as corrosion inhibitor for Aluminum in acid media Experimental and theoretical study
}

\author{
Haider A. Abood \\ Material Engineering Department - College of Engineering - university of Basrah
}

\begin{abstract}
$\underline{\text { Abstract }}$
The effects of Meloxiam drug (MEL) on the corrosion of pure aluminum in $2 \mathrm{M} \mathrm{HCl}$ have been investigated using weight loss methods. The measurement showed that the inhibition efficiency increased with increase in the concentration of inhibitor. The adsorption of the inhibitors on the aluminum surface obeyed Langmuir adsorption isotherm and had a physical mechanism. The effect of temperature on the corrosion behavior in the presence of different concentration of the MEL inhibitors was studied in the temperature range of $25-65{ }^{\circ} \mathrm{C}$. The associated activation energy of corrosion $\mathrm{E}_{\mathrm{a}}$ and other thermodynamic parameters such as $\Delta H^{0}{ }_{a d s}, \Delta S_{\text {ads }}^{0},\left(\mathrm{~K}_{\mathrm{ads}}\right)$ and $\Delta G^{0}{ }_{a d s}$ were calculated to elaborate the mechanism of corrosion inhibition. Quantum chemical parameter such as HOMO,LUOM and Mulliken charge etc. have been calculated using DFT (B3LYP/ 6$311++\mathrm{G}(\mathrm{d}, \mathrm{p}))$, The results indicate that $\mathrm{N}$ and $\mathrm{S}$ atoms in the MEL structure was not effected in the adsorption of drug on the Al surface .
\end{abstract}

Key word: Corrosion inhibitors, Aluminium metal, Quantum chemical calculation

\section{الخلاصة}

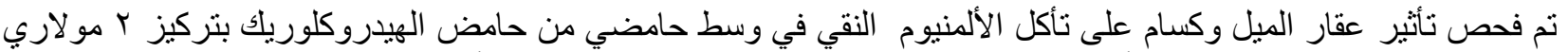

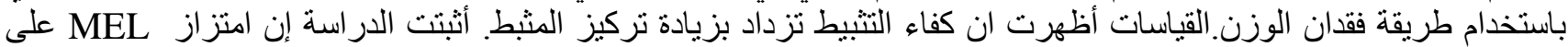

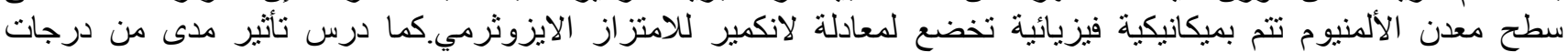

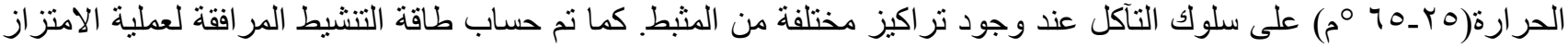

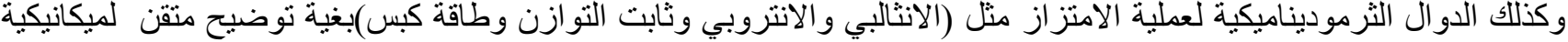

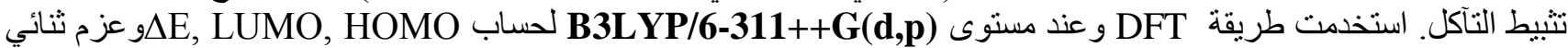

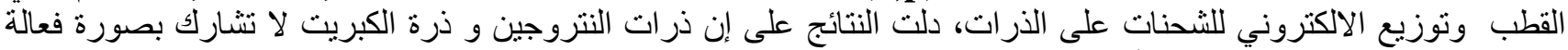
بعملية الامتز از على سطح معدن الألمنيوم. 


\section{1-Introduction:}

Among all the metals, aluminum has been one of the most common metals used for industrial and domestic purposes due to its excellent electrical conductivity, good forming proprties, low cost and other relatively noble properties. It is a material commonly used in aerospace and household industries, and it is also used for reaction vessels, pipes, machinery and chemical batteries. A variety of environmental factors can easily cause corrosion of aluminum. Hydrochloric acid $(\mathrm{HCl})$ solutions are used for pickling, chemical and electrochemical etching of Al. It is very important to add corrosion inhibitors to decrease the corrosion rate of $\mathrm{Al}$ in such solutions. Thus, aluminum corrosion and its inhibition have attracted the attention of a number of investigators [1-6].

A variety of organic compounds have been reported to be effective as corrosion inhibitors during acidization in industrial cleaning processes [7-11].

Unfortunately, most of the organic inhibitors used are very expensive and health hazards. Their toxic properties limit the field of their application. However, only a few non-toxic and ecofriendly compounds have been investigated as pickling inhibitors. Tryptamine [12], succinic acid [13], L ascorbic acid [14] and sulfamethoxazole [15] were found to be effective inhibitors in acid environments. Among dithiobiurets (organic compounds containing $\mathrm{N}$ and $\mathrm{S}$ atoms have very low toxicity), Quraishi et al. [16] found that 1-anisidyl-5-phenyl-2,4-dithiobiuret

(APDTB) exhibited the best performance towards the corrosion of mild steel in $\mathrm{HCl}$ solutions. The inhibitive action of four antibacterial drugs, namely, ampicillin (Amp), cloxacillin (Clox), flucloxacillin (Fluclox) and amoxicillin (Amox) toward the corrosion of $\mathrm{Al}$ in $\mathrm{HCl}$ solution was investigated [17].

The under study anti-inflammatory drug 4-hydroxy-2-methyl- $N$-(5-methyl1,3-thiazol-2-yl)-2 $H$-1,2-benzothiazine - 3 - carboxamide 1,1-dioxide (MEL) compound satisfy these requirements [18]. The compound have a large number of functional adsorption centers (e.g. - $\mathrm{OH}$ group, $-\mathrm{SO} 2-\mathrm{NH}-$ group, $\mathrm{S}$ and/or $\mathrm{N}$ hetero atoms and aromatic rings). They are strongly basic, hence they can be readily soluble in the acid medium.

Recently, quantum chemical calculations have been widely used to study reaction mechanism. They have also proved to be a very important tool for studying corrosion inhibition mechanism [18,19]. In recent times, Density Functional Theory (DFT) has become an attractive theoretical method because it gives exact basic vital parameters for even huge complex molecules at low cost. Furthermore, by using sophisticated computational tools, [20] . Thus, the DFT has become a main source of connecting some traditional empirical concepts with quantum mechanics. Therefore, DFT is a very powerful technique to probe the inhibitor/surface interaction and to analyze experimental data.

The aim of this work was to study the inhibition of Aluminum corrosion by MEL in $2 \mathrm{M} \mathrm{HCl}$ solutions in the temperature range of $25-65 \mathrm{C}$. The adsorption behavior of MEL was also analyzed in order to choose the appropriate adsorption isotherm.

\section{Experimental}

\subsection{Inhibitor}


MEL was purchased from medicine shop in Basrah as a trade name Meloxicam tablet and used with further Purification according [21,22] (m.p. $=463^{\circ}$ K). Fig. 1 shows the molecular structure of MEL.MEL is a N-S heterocyclic compound containing two nitrogen atoms which could be easily protonated in acid solution, and a great deal of $\mathrm{p}$ electrons exists in this molecule. The concentrations range of the inhibitor used was $\left(1 \times 10^{-4}-1 \times 10^{-3} \mathrm{M}\right)$.<smiles>Cc1cnc(NC(=O)C2=C(O)c3ccccc3S(=O)(=O)N2C)s1</smiles>

4hydroxy-2-me thyl-H-(5-me thyl-1,3-thiazol-2-yl)-2 H-1,2-benzothiazine-3-carboxamide 1,1-dioxide

Fig .1: Shows the molecular structure of Meloxiam (MEL)[21]

\subsection{Specimens preparation}

Prior to all measurements, the rectangular pure aluminum $99.99 \%($ $2.84 \mathrm{~cm} \times 1.13 \mathrm{~cm} \times 0.23 \mathrm{~cm}$ ) [from $\mathrm{Ur}$ State company for Engineering Industries-Aluminum production and manufacture factories in Nasiriah] were ground with different emery paper up to 1000 grade, washed thoroughly with bidistilled water, degreased and dried with acetone. The aggressive solution (2 $\mathrm{M} \mathrm{HCl}$ ) was prepared by dilution of analytical grade with bidistilled water. The solution volume was $100 \mathrm{~cm}^{3}$.

\subsection{Weight loss experiment}

Pure aluminum specimens in triplicate for each inhibitor concentration were immersed in the acid solutions for
$3 \mathrm{~h}$ at different temperature. The temperature was controlled by an aqueous thermostat. After that, the specimens were removed, rinsed in water and acetone, and dried in desiccator. Then the loss in weight was determined by analytical balance $( \pm 0.1 \mathrm{mg})$. The corrosion rate $(v)$ value of weight loss measurement was calculated from the following equation [23]:

$$
v=\Delta \mathrm{W} / \mathrm{St}
$$

where $\Delta \mathrm{W}$ is the average weight loss of three parallel Al sheets, $S$ the total surface area of the specimen, and $t$ is the immersion time $(3 \mathrm{~h})$. With the calculated corrosion rate, the inhibition 
efficiency (I\%) was calculated as follows [24]:

$\mathrm{I} \%=v_{0}-v / v \times 100$

where $v_{0}$ and $v$ represent the values of the corrosion rate without and with addition of the inhibitor, respectively.

\subsection{Quantum chemical study}

The molecular structure of the MEL had been fully geometric optimize by DFT (B3LYP/ 6-311++G(d,p)) with Gaussian 03 software package [25], the quantum chemical indices such as the highest occupied molecular orbital (HOMO), the lowest unoccupied molecular orbital (LUMO), energy gap $(\Delta \mathrm{E}=\mathrm{HOMO}-\mathrm{LUMO})$, and dipole moment $(\mu)$ were considered.

\section{Result and Discussion}

\subsection{Corrosion rate and inhibition efficiency}

The inhibiting effect of MEL on the corrosion of aluminium $2 \mathrm{M} \mathrm{HCl}$ was investigated using gravimetric technique. Fig.2 illustrates the variation of weight loss with time for aluminium corrosion in the absence and the presence of different concentrations of MEL at 35 ${ }^{\circ} \mathrm{C}$. The plots show that MEL inhibits aluminium corrosion in the acidic environment. Corrosion rates in inhibited systems decreased with increasing concentration of MEL, suggesting that the inhibiting effect of the drug on aluminium corrosion in $2 \mathrm{M}$ $\mathrm{HCl}$ is concentration dependent. Similar curve not shown have been obtained for the other temperatures under study.

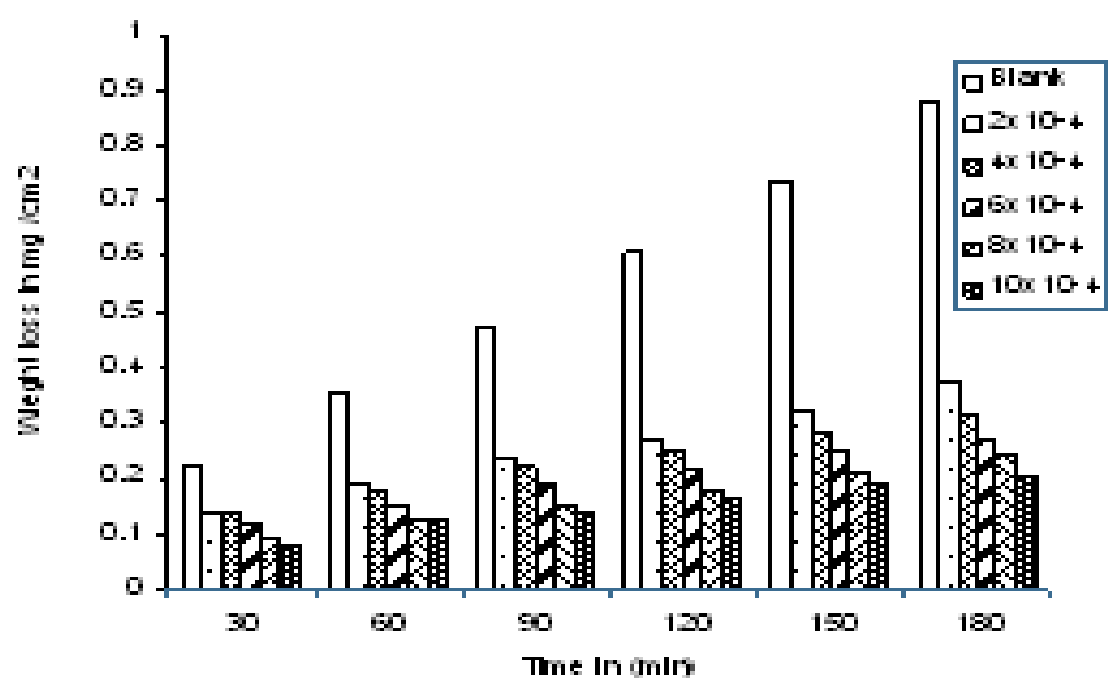

Fig.2: Weight loss-time curve for the corrosion of $\mathrm{Al}$ in $2 \mathrm{M} \mathrm{HCl}$ in the absence and in the presence of different concentration of MEL at $35^{\circ} \mathrm{C}$. 
Fig. 3 compares the corrosion rates in the absence and presence of inhibitor at different temperatures after $3 \mathrm{~h}$ immersion period. The results indicate that introduction of MEL abridged aluminium dissolution at all temperatures studied and all concentrations used in study. Corrosion rate decreased with increasing

inhibitor concentration. This may be due to the adsorption of MEL at the $\mathrm{Al}$ surface also corrosion rates in inhibited as well as uninhibited systems increased with rise in temperature.

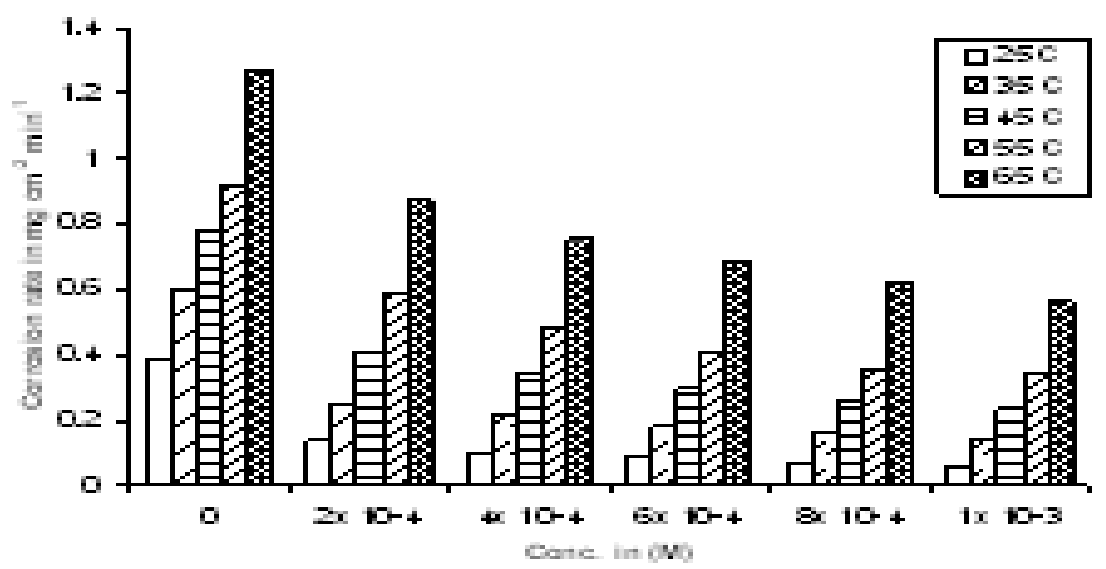

Fig .3: Variation of corrosion rate of $\mathrm{Al}$ at versus concentration of MEL drug

The corrosion behaviour of the aluminium specimen in the presence of MEL indicates that the drug molecules were adsorbed through nonbonding electron pairs present on nitrogen, sulfur and oxygen atoms as well as $\pi$-electrons [26] over the Al surface and that surface coverage changed with temperature as well as concentration of the drug. As presented in Table 1, inhibition efficiency increased with MEL concentration at all temperatures. The trend of $\mathrm{I} \%$ with temperature however follow a steady relationship.

Table 1: Corrosion parameters for $\mathrm{Al} 7075$ in aqueous solution of $1 \mathrm{M} \mathrm{HCl}$ in absence and presence of different concentrations of MEL from weight loss measurements at $35{ }^{\circ} \mathrm{C}$ for $3 \mathrm{~h}$.

\begin{tabular}{|c|c|c|c|c|c|}
\hline $\begin{array}{c}\text { Concentration } \\
\text { Temp. } \\
\text { in }\end{array}$ & \multicolumn{5}{|c|}{ Inhibition Efficiency I\% } \\
\cline { 2 - 6 } & 25 & 35 & 45 & 55 & 65 \\
\hline $2 \times 10^{-4}$ & 64.3 & 57.504 & 47.442 & 37.012 & 31.077 \\
\hline $4 \times 10^{-4}$ & 73.491 & 64.249 & 56.138 & 47.835 & 40.755 \\
\hline $6 \times 10^{-4}$ & 77.63 & 69.477 & 62.276 & 55.519 & 47.757 \\
\hline $8 \times 10^{-4}$ & 81.57 & 72.344 & 67.263 & 59.74 & 51.14 \\
\hline $1 \times 10^{-3}$ & 85.301 & 76.391 & 70.332 & 64.445 & 55.704 \\
\hline
\end{tabular}


Maximum inhibition efficiency shown at $1 \times 10^{-3} \mathrm{M}$ concentration of the inhibitor in $2 \mathrm{M} \mathrm{HCl}$ at $25{ }^{\circ} \mathrm{C}(85.301)$, The high inhibitive performance of MEL suggests a higher bonding ability of inhibitor to the Al surface, which possess higher number of lone pairs on hetero atoms and p-orbitals.
The influence of solution temperature on inhibition efficiency is shown in fig.4 . It is observed that inhibition efficiency decreases with increase in temperature from 25 to $65^{\circ} \mathrm{C}$. The decrease in inhibition efficiency with temperature may be

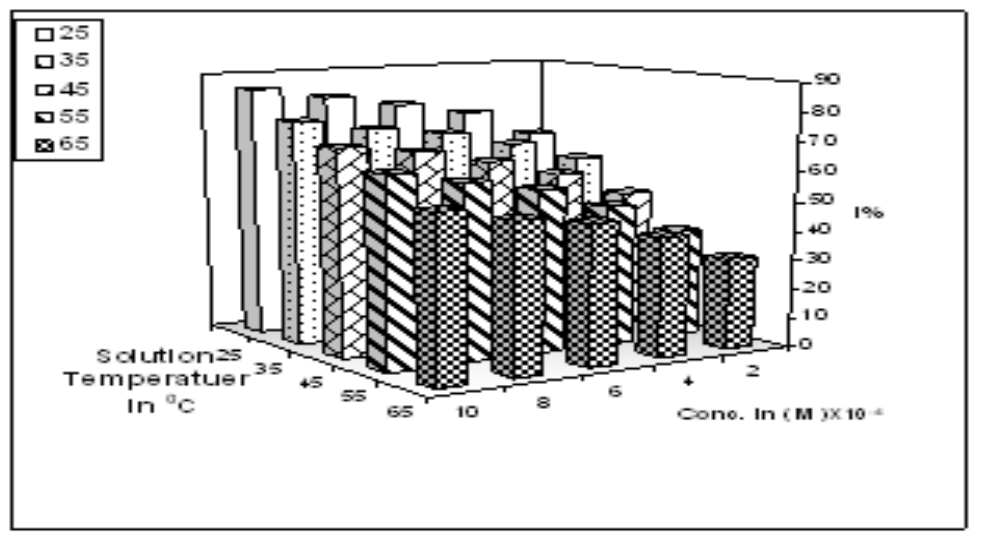

Fig. 4: Effect of different Conc. and temperature on the inhibition efficiency

attributed to desorption of the inhibitor molecule from metal surface at higher temperature [27]. Corrosion of $\mathrm{Al}$ in acidic environments is generally accompanied with hydrogen gas evolution and increase in temperature usually accelerates the evolution of hydrogen which results in higher dissolution rate of

$2 \mathrm{Al}_{(\mathrm{s})}+6 \mathrm{HCl}_{(\mathrm{l})} \longrightarrow 2 \mathrm{AlCl}_{3}+3 \mathrm{H}_{2}$ (gas)

the $\mathrm{Al}[28]$. The decrease in inhibition efficiency may be probably due to increased rate of desorption at higher temperatures. also the increase in concentration of inhibitor lead to increase the inhibition efficiency at the same temperature.

\subsection{Thermodynamic parameters and adsorption isotherm}

It is generally accepted that organic molecules inhibit corrosion by adsorption at the metal surface and the adsorption depends on the molecule's chemical composition. Basic information on the adsorption of inhibitor on metals surface can be provided by adsorption isotherm. Attempts were made to fit the experimental data to various isotherms including Frumkin, Langmuir, Temkin, Freundlich , Bockris-Swinkels and Flory-Huggins isotherms. By far the results were best fitted by Langmuir adsorption isotherm equation [29]:

$$
\frac{C}{\theta}=\frac{1}{K_{a d s}}+C
$$

where $c$ is the concentration of inhibitor, $K_{a d s}$ the adsorptive equilibrium constant, and $\theta$ represents the Surface coverage values for the inhibitor were obtained from the $\theta=\mathrm{I} \% / 100$ for various concentrations at the studies range temperatures.

The best fitted straight line is obtained for the plot of $\mathrm{C} / \theta$ versus $\mathrm{C}$, from the intercepts of the straight lines 
on the $\mathrm{C} / \theta$-axis, $\mathrm{K}_{\mathrm{ads}}$ values can be calculated as shown in Fig. 5. The strong correlation $\left(\mathrm{R}^{2}\right)$ as shown in Table 2 . are almost nears one, suggests that the adsorption of MEL inhibitor on the metal surface obeyed to the Langmuir's adsorption isotherm [30], also from table 2 indicates

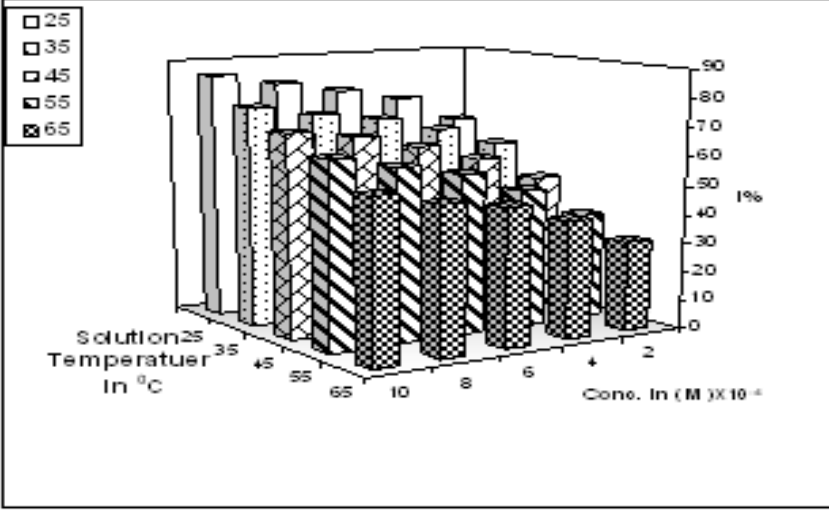

Fig. 5: Langmuir isotherm adsorption model of MEL at different Conc. on the aluminium surface.

that the adsorptive equilibrium constant $K_{a d s}$ values decrease with the increase of temperature . Large values of $K_{a d s}$ mean better inhibition efficiency of a given inhibitor and it is in good agreement with the previous work [31].

Table 2: Adsorption parameters deduced from Langmuir adsorption isotherms

\begin{tabular}{|c|c|c|c|}
\hline Temperature in ${ }^{\circ} \mathbf{C}$ & Slope & $\mathbf{R}^{2}$ & $\mathbf{K}\left(\mathbf{M}^{-1}\right)$ \\
\hline 25 & 1.12 & 0.998 & 10526.31 \\
\hline 35 & 1.025 & 0.9979 & 8333.33 \\
\hline 45 & 1.125 & 0.997 & 5000 \\
\hline 55 & 1.05 & 0.9968 & 3125 \\
\hline 65 & 1.69 & 0.997 & 2777.22 \\
\hline
\end{tabular}

Standard free energy of adsorption, $\Delta G_{\text {ads }}$ relate the $K_{a d s}$ as given by the following equation [32]:

$\Delta \mathrm{G}_{\mathrm{ads}}^{\circ}=-2.303 \mathrm{RT} \log \left(55.5 \mathrm{~K}_{\mathrm{ads}}\right)$

The calculated free energies $\left(\Delta G^{0}{ }_{a d s}\right)$ are given in Table 3; the negative values of $\Delta G^{0}$ ads indicate spontaneous adsorption of MEL on the Al surface as well as a strong interaction between the inhibitor molecules and the metal surface[33]. Generally, values of $\Delta G^{0}$ ads up to -20 $\mathrm{kJ} / \mathrm{mol}$ are consistent with physisorption,
While those around $-40 \mathrm{~kJ} / \mathrm{mol}$ or higher are associated with chemisorptions as a result of the sharing or transfer of electrons from organic molecules to the metal surface to form a coordinate [34].

Table 3: Thermodynamic parameters of adsorption of MEL on the $\mathrm{Al}$ surface

\begin{tabular}{|c|c|c|c|}
\hline Temperature in ${ }^{\circ} \mathrm{C}$ & 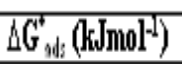 & $\Delta \mathrm{H}\left(\mathrm{kJ} \mathrm{mol}^{-1}\right)$ & $\Delta \mathrm{S}\left(\mathrm{kJ} \mathrm{Mnol}^{-1}\right)$ \\
\hline 25 & .32 .9 & .36 .581 & .0 .123 \\
\hline 35 & .33 .4 & -36.581 & -0.0103 \\
\hline 45 & .33 .14 & .36 .581 & 0.0108 \\
\hline 55 & 32.82 & .36 .581 & 0.0112 \\
\hline 65 & .33 .57 & .36 .581 & .0.0089 \\
\hline
\end{tabular}


The values of $\Delta G_{a d s}^{0}$ in our measurement was less than $-40 \mathrm{~kJ} / \mathrm{mol}$ ,suggesting that MEL strong physisorped on aluminium surface .

Thermodynamically, $\Delta G_{a d s}^{0}$ is related to the standard enthalpy and entropy of the adsorption process, $\Delta H^{0}$ ads and $\Delta S^{0}{ }_{a d s}$, respectively, via Eq. (5): $\Delta G^{0}{ }_{a d s}=\Delta H_{a d s}^{0}-T \Delta S_{\text {ads }}^{0}$

and the standard enthalpy of adsorption $\left(\Delta H_{a d s}^{0}\right)$ can be calculated according to the van't Hoff equation [35]:

$$
\ln K_{a d s}=\frac{-\Delta H^{0}}{R T}+\text { Const. }
$$

A plot of $\ln K_{a d s}$ versus $1 / T$ gives a straight line, as shown in Fig. 6. The slope of the straight line is $-\Delta H_{a d s}^{0} / R$. The value of $\Delta \mathrm{H}^{0}$ ads is given in Table 3 . Since the $\Delta \mathrm{H}^{0}$ ads value is negative, the adsorption of inhibitor molecules onto the $\mathrm{Al}$ surface is an exothermic process. In an exothermic process, chemisorption is distinguished from physisorption by considering the absolute value of $\Delta \mathrm{H}^{0}$ ads; for the chemisorption process, it approaches $100 \mathrm{~kJ} / \mathrm{mol}$, while for the physisorption process, it is less than 40 $\mathrm{kJ} / \mathrm{mol}$ [36]. In the present study, the $\Delta \mathrm{H}^{0}$ ads (physical adsorption heat )value is slightly small, once again implying that physical adsorption is taking place.

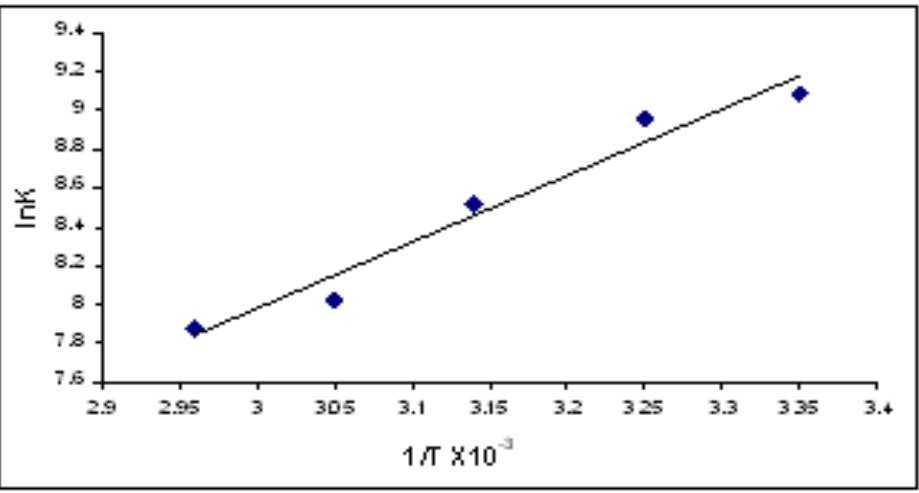

Fig.6: Plots of $\operatorname{lnk}\left(\right.$ equilibrium constant) versus $1 / \mathrm{T} \times 10^{3}$

The standard entropy of inhibitor adsorption, $\Delta S^{0}{ }_{a d s}$, can be calculated from Eq. (5). The calculated values of $\Delta S^{0}{ }_{a d s}$ are recorded in Table 3 . It is obvious that the values of $\Delta S_{a d s}^{0}$ are negative, as inhibitor molecules move freely in the bulk solution (are chaotic) before adsorption, while as adsorption progresses, the inhibitor molecules adsorbed onto the Al surface become more orderly, resulting in a decrease in entropy [37].

Plots of $\ln v$ vs. 1/T for pure aluminum in $2 \mathrm{M} \mathrm{HCl}$ in absence and presence of various concentrations of MEL are shown in fig.7 .As shown a straight line were obtained according to Arrhenius type equation:

$$
v=A \exp \left(-\frac{E_{a}}{R T}\right)
$$

Were $v$ is the corrosion rate in $\mathrm{mg} \mathrm{cm}$ $\min ^{-1}, \mathrm{~A}$ is constant depends on a metal type and electrolyte, $\mathrm{E}_{\mathrm{a}}$ is the apparent activation energy, $R$ is gas constant and is the absolute temperature. Values of $\mathrm{E}_{\mathrm{a}}$ were determined in the presence and absence of MEL . The $E_{a}$ in free acid solution is equal to $29.098 \mathrm{kJmol}^{-1}$ which is of the same order of magnitude as those observed by Ashassi et al [38] 
Table 4: Values of the activation energy and regression between $\operatorname{lnk}$ and

\begin{tabular}{|c|c|c|}
\hline Conc. (M) & $\operatorname{Ea}\left(\mathrm{kJmol}^{1}\right)$ & $R^{2}$ \\
\hline 0 & 29.098 & 0.9805 \\
\hline $2 X 10^{-7}$ & 33.256 & 0.9927 \\
\hline $4 X 10^{-}$ & 37.413 & 0.9847 \\
\hline $6 \mathrm{Kl} 0^{-7}$ & 37.413 & 0.9807 \\
\hline $8 K 10^{-7}$ & 39.419 & 0.9813 \\
\hline$\left[X 10^{\prime}\right.$ & 43.648 & 0.9872 \\
\hline
\end{tabular}

Generally one can say the nature and the concentration of electrolyte affect greatly the activation energy for the corrosion process, also the relative small values of activation energy of the inhibited corrosion reaction indicate a physical adsorption takes place in the first stage. This behaviour is due to an increase in surface area of metal covered by MEL [39].

MEL planer molecules .The binding capability of a molecule depend on the

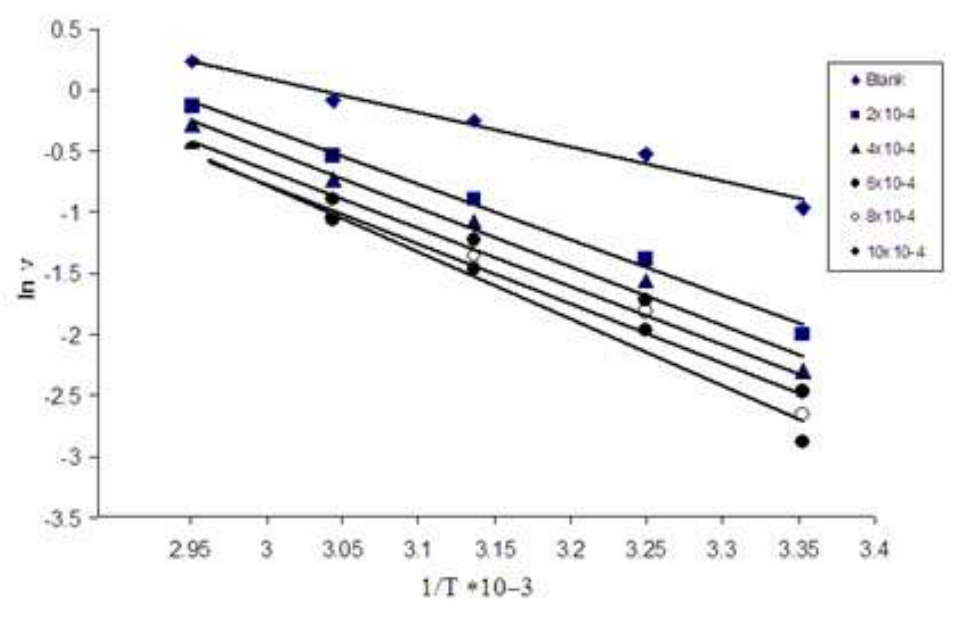

Fig.7: Plots of $\ln v\left(\right.$ corrosion rate) versus $1 / \mathrm{T} \times 10^{-3}$ for different Concentration.

\subsection{Quantum calculation}

In order to obtain more information about the electronic structure and the inhibitory action of the MEL compound, Density function theory (DFT) calculations were performed using DFT(B3LYP / 6-311++G(d ,p)) methods. Fig. 8a shows a full geometry optimization of the MEL molecules. It shows that the thiazol ring and substitution $-\mathrm{NH}$ group are in the same one plane with benzene ring so the electronic charge on the chelating atom thus ,the values were obtained by the Mulliken population analysis . Fig.8b presents Mulliken charge of the atoms in MEL molecule. 
a)

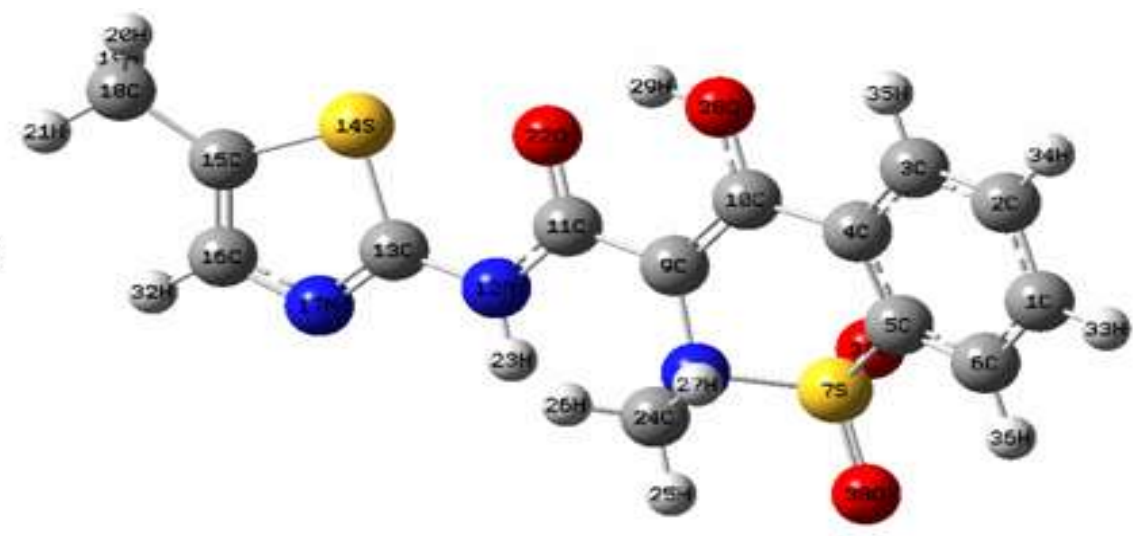

b)

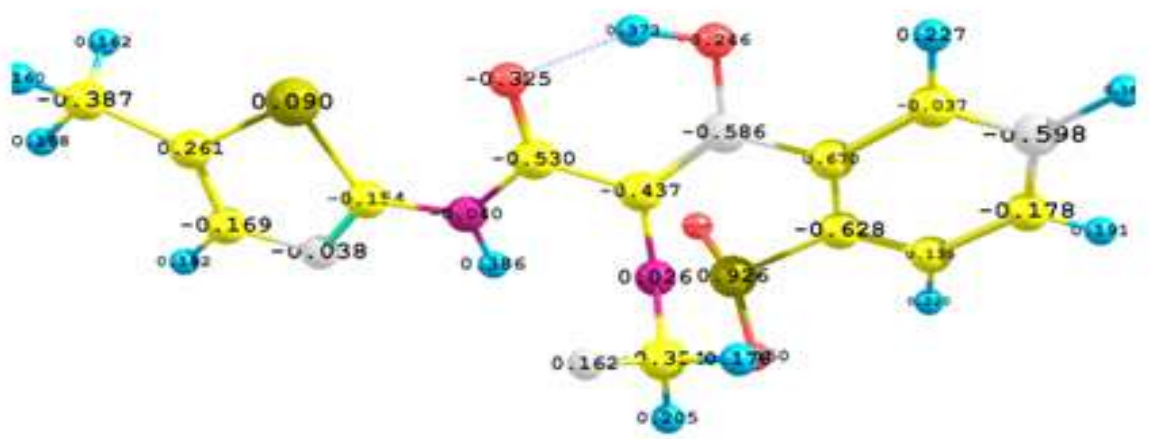

Fig.8 : Explain a)The optimization molecular structure of MEL and b) Mulliken charges of the atoms in MEL molecule

By careful examination of the values of Mulliken charges, the larger negative charge of atoms are found in (C9,C10,C11,O22, O28, and ,C1 ,C2, $\mathrm{C} 5$ at the phenyl ring also $\mathrm{C} 13$ and $\mathrm{C} 16$ in the thiazol five member ring) which connect to the donating electrons, and could donate its lone electron pair to the unfilled orbital of the metal atom, the MEL molecule can be adsorbed on the metal surfaces by the above atoms .

The quantum chemical indices energies $\mathrm{E}_{\mathrm{HOMO}}, \mathrm{E}_{\mathrm{LumO}}$, and $\Delta \mathrm{E}$ have been calculated, were $\left(\Delta \mathrm{E}=\mathrm{E}_{\mathrm{LUMO}}-\mathrm{E}_{\mathrm{HOMO}}\right)$ is the gap between $\mathrm{E}_{\mathrm{HOMO}}$ and $\mathrm{E}_{\mathrm{LumO}}$. The smaller energy gap $(\Delta \mathrm{E})$ obtained $(3.595 \mathrm{eV})$ to $\mathrm{MEL}$ can be interpreted by a stronger adsorption bond and perhaps greater inhibitor efficiency [40]. As
$\mathrm{E}_{\mathrm{HOMO}}$ is often associated with the electron donating ability of molecule, high values of $\mathrm{E}_{\text {HOMO }}$ are likely to indicate a tendency of the molecule to donate electrons to appropriate acceptor molecules with low energy, empty molecular orbitals. Increasing values of the $\mathrm{E}_{\text {HOMO facilitate adsorption (and }}$ therefore inhibition) by influencing the transport process through the adsorbed layer [41]. $\mathrm{E}_{\mathrm{LuMO}}$, the energy of the lowest unoccupied molecular orbital indicates the ability of the molecules to accept electrons. The lower value of $\mathrm{E}_{\mathrm{LUMO}}$, the more probable, it is that the molecule would accept electrons [41] . The obtained $\mathrm{E}_{\text {Hомо }}(-6.268 \mathrm{eV})$ which it high comparing with Lie at [42] and Yan at[43] also the $\mathrm{E}_{\mathrm{LuMO}}$ value is $2.673 \mathrm{eV}$ which it small than the results given by above researcher. This may 
explain the good inhibition efficiency of MEL molecule is due to increasing energy of the HOMO and the decreasing energy of the LUMO. Fig.9 shows the frontier orbital density distribution of HOMO and LUMO.

a) HOMO

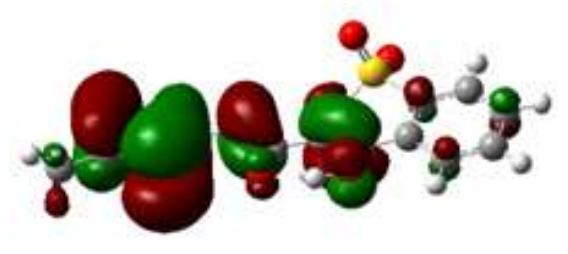

b) LUMO

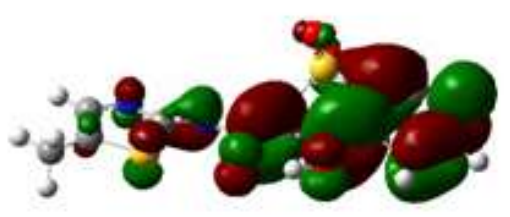

Fig.9: Three dimensions pictures of frontier orbital density distribution

a) HOMO and b)LUMO

The dipole moment $(\mu)$ is another indicator of the electronic distribution in a molecule and is one of the properties used to discuss and to rationalize the structure [ 44 ]. The high value of dipole moment probably increases the inhibitor adsorption and increase of inhibition efficiency [ 41] the dipole moment of the MEL is 4.3523 Debye which relatively agreement to the literature including the correlation between the dipole moment and inhibition efficiency[ 40,45].

\section{$\underline{\text { References }}$}

[1] C.Vargel Corrosion of Aluminium , Elsevier Ltd, Netherlands (2004).

[2] F.-H. Cao, Z. Zhang*, J.-F. Li, Y.-L. Cheng,J.-Q. Zhang and C.-N. Cao ;" Exfoliation corrosion of aluminum alloy AA7075 examined by electrochemical impedance spectroscopy " Materials and Corrosion 55 (2004)18-23.
[3] M. A. Amin, S. Abd EI-Rehim, E.F. ElSherbini, O. A. Hazzazi , M. N.bbas ; " Polyacrylic acid as a corrosion inhibitor for aluminium in weakly alkaline solutions. Part I: Weight loss, polarization, impedance EFM and EDX studies" Corros. Sci. 51 (2009) 658-667.

[4]A.Y. El-Etre ;" Inhibition of aluminum corrosion using Opuntia extract" Corros. Sci. 45 (2003) 2485-2495.

[5]D. Mercier 1, M.-G. Barthés-Labrousse :" The role of chelating agents on the corrosion mechanisms of aluminium in alkaline aqueous solutions" Corros. Sci. ;51 (2009) 339-348

[6]J.B. Bajat , V.B. MiškovicStankovic, Z. Kac `arevic.Popovic:" Corrosion stability of epoxy coatings on aluminum pretreated by vinyltriethoxysilane"Corros. Sci. 50 (2008) 2078-2084. 
[7]M. Elachouri, M.S. Hajji, S. Kertit, E.M. Essasi, M. Salem, R. Coudert;" Some surfactants in the series of 2(alkyldimethylammonio) alkanol bromides as inhibitors of the corrosion of iron in acid chloride solution"Corros. Sci.37 (1995) 381389.

[8] B. Mernari, H. El Attari, M. Traisnel, F. Bentiss, M. Lagrenee;" Inhibiting effects of 3,5-bis(n-pyridyl)-4-amino1,2,4-triazoles on the corrosion for mild steel in $1 \mathrm{M} \mathrm{HCl}$ medium" Corros. Sci. 40 (1998) 391-399.

[9] M. ElAchouri, S. Kertit, H.M. Gouttaya, B. Nciri, Y. Bensouda, L. Perez, M.R.Infante and K. ElKacemi ;" Corrosion inhibition of iron in $1 \mathrm{M}$ $\mathrm{HCl}$ by some gemini surfactants in the series of alkanediyl- $\alpha, \omega$-bis-(dimethyl tetradecyl ammonium bromide)"Prog. Org. Coat. 43 (2001) 267-273.

['·]F. Zucchi, G. Trabanelli, G. Brunoro;" Iron corrosion inhibition in hot $4 \mathrm{M}$ $\mathrm{HCl}$ solution by $t$-cinnamaldehyde and its structure-related compounds"Corros. Sci. 36 (1994) 1683-1690.

[' ']A. Cizek;" Acidizing Inhibitors" Mater. Perform. 33 (1994) 56.

$\left[{ }^{Y}\right]$ W.W. Frenier, F.B. Growcock, in: A. Raman, P. Labine (Eds.), Review on Corrosion Science and Technology, NACE International, Houston, TX, (1993), pp11-201.

[1ॅ]G. Moretti, F. Guidi, G. Grion;" Tryptamine as a green iron corrosion inhibitor in $0.5 \mathrm{M}$ deaerated sulphuric acid" Corros. Sci. 46 (2004) 387403.

[1๕]F.C. Giacomelli, C. Giacomelli, M.F. Amadori, V. Schmidt, A.Spinelli;" Inhibitor effect of succinic acid on the corrosion resistance of mild steel: electrochemical, gravimetric and optical microscopic studies" Mater. Chem. Phys. 83 (2004) 124-128.

[10]E.S. Ferreira, C. Giacomelli, F.C. Giacomelli, A. Spinelli;" Evaluation of the inhibitor effect of L-ascorbic acid on the corrosion of mild steel" Mater.Chem. Phys. 83 (2004) 129134.

[17]E.E. Foad El Sherbini;" Effect of some ethoxylated fatty acids on the corrosion behaviour of mild steel in sulphuric acid solution"Mater. Chem. Phys. 60 (1999) 286-290.

[1`]M.A. Quraishi, J. Rawat, M. Ajmal ;" Dithiobiurets: a novel class of acid corrosion inhibitors for mild steel"J. Appl. Electrochem. 30 (2000)745751.

[1^]M. Abdallah;'Antibacterial drugs as corrosion inhibitors for corrosion of aluminium in hydrochloric solution" Corros. Sci. 46 (2004) 1981-1996.

[19]I.B. Obot, N.O. Obi-Egbedi ;" Fluconazole as an inhibitor for aluminium corrosion in $0.1 \mathrm{M}$ $\mathrm{HCl}$ Colloids and surfaces A: Physicochem.Eng. Aspects 330(2008) 207.

[ץ.]I.B. Obot, N.O. Obi-Egbedi;" Inhibitory effect and adsorption characteristics of 2,3-diaminonaphthalene aluminum/hydrochloric acid interface: Experimental and theoretical study $I^{\prime \prime}$ Surf. Rev. Lett. 15(6) (2008) 903.

[2)] I.B. Obot, N.O. Obi-Egbedi, S.A. Umoren;" The synergistic inhibitive effect and some quantum chemical parameters of 2,3-diaminonaphthalene and iodide ions on the hydrochloric acid corrosion of aluminium"Corros. Sci. 51 (2009) 276. 
[2r]A.C.Moffat,J.V.Jacson,M.S.Moss and E.S.Gree"Clarkes Isolation and Identification of Drug " The paramedical press ,Londen (1986).

$\left[2^{\top}\right]$ H.A.Abood;"Synthesis and theoretical of $\mathrm{Cu}(\mathrm{II})$ and $\mathrm{V}(\mathrm{IV})$ with 2-(2,3dimethyl phenylb)amino benzoic acid ligands and 2-(2,5-dichloro phenyl) amino phenyl acetic acid" Basrah Journal of Science (C),24(2006)4867.

[2§]R.A. Prabhu, T.V. Venkatesha, A.V. Shanbhag , G.M. Kulkarni , R.G. Kalkhambkar ;" Inhibition effects of some Schiff's bases on the corrosion of mild steel in hydrochloric acid solution"Corros. Sci. $50 \quad$ (2008) 3356-3362.

[2०]M. Scendo ;" Inhibition of copper corrosion in sodium nitrate solutions with nontoxic inhibitors"Corros. Sci. 50 (2008) 1584-1592.

[27]M.J.Frish at al. : GAUSSIAN 03 program, Ggaussian Inc.(2004).

$\left[2^{\vee}\right]$ M. Bouklah a, N. Benchat b, B. Hammouti, A. Aouniti a, S. Kertit; "Thermodynamic characterisation of steel corrosion and inhibitor adsorption of pyridazine compounds in $0.5 \mathrm{M} \mathrm{H}_{2} \mathrm{SO}_{4}$ "Materials Letters 60 (2006) 1901-1905.

[2^] Q. Zhang and YiXin Hua; "Corrosion inhibition of aluminum in hydrochloric acid solution by alkylimidazolium ionic liquids"Mater, Chem. and Phys. 119 (2010) 57-64.

[29]G.O.Avwiri and F.O.Igho:" Inhibitive action of Vernonia amygdalina on the corrosion of aluminium alloys in acidic media" Material Letters 57(2003)3705-3711 $\left[{ }^{\Gamma \cdot}\right]$ K. Tebbji , I. Bouabdellah , A. Aouniti , B. Hammouti, H. Oudda, M.

Benkaddour and A. Ramdani ; "Nbenzyl- $N, N$-bis[(3,5-dimethyl-1 $H$ -

pyrazol-1-yl)methyl]amine as corrosion inhibitor of steel in $1 \mathrm{M}$ $\mathrm{HCl}$ "Materials Letters 61 (2007) 799-804.

[3']E.E. Oguzie, G.N. Onuoha, A.I. Onuchukwu ;" Inhibitory mechanism of mild steel corrosion in $2 \mathrm{M}$ sulphuric acid solution by methylene blue dye " Mater. Chem.y and Phys. 89 (2005) 305-311.

[3ץ]H.A.Abood ;"Inhibitive effect of hydrochlorothiazoide on the corrosion of aluminum 7075 in $0.1 \mathrm{M} \mathrm{HCl}$ and its adsorption characteristics" Journal of Basrah Reasearches(Sci.)36(2010),1.

[3ॅ]E. E.Ebenso, 1, N. O. Eddy, and A. O Odiongenyi;" Corrosion inhibitive properties and adsorption behaviour of ethanol extract of Piper guinensis as a green corrosion inhibitor for mild steel in $\mathrm{H}_{2} \mathrm{SO}_{4}$ " African Journal of Pure and Applied Chemistry 2 (2008) 11, 107-115.

[3 ] ]EE.Ebenso,U.J.Ekpe,S.A.Umoren,E.Jac kson,O.K.Abiola and N.C.Oforka ;" Synergistic effect of halide ions on the corrosion inhibition of aluminum in acidic medium by some polymers" J.Appl . Poly. Sci. 100(2006)28892894

[35]S.Bilgic and M.Sahin ; "The corrosion inhibition of austenitic chromiumnickel steel in $\mathrm{H}_{2} \mathrm{SO}_{4}$ by 2-butyn-1ol"Mater.Chem.Phys.70(2001)290.

[36]X.H.Li, ,S.D.Deng,G.N.Mu,H.Mu,H.Fu and F.Z.Yang ; "Synergistic inhibition effect of rare earth cerium(IV) ion and anionic surfactant on the corrosion of cold rolled steel in $\mathrm{H}_{2} \mathrm{SO}_{4}$ solution"Corros.Sci. 50(2008)2635. 
[37]W.Durnie, R.DeMarco , B.Kinsella and A.Jefferson ;" Development of a

Field Corrosion Inhibitors" J. Electrchem. Soc.146(1999)5 ,1751.

[3^]S.Martinez and I.Stren ;" Thermodynamic characterization of metal dissolution and inhibitor adsorption processes in the low carbon steel/mimosa tannin/sulfuric acid system"Appl. Surf. Sci. ;199(2002)83.

[39]H.Ashassi-Sorkhabi,Z.Ghasemi and D.Seifzadeh ;" The inhibition effect of some amino acids towards the corrosion of aluminum in $1 \mathrm{M}$ $\mathrm{HCl}+1 \mathrm{M} \quad \mathrm{H}_{2} \mathrm{SO}_{4}$ solution"Applied Surface Science 249(2005) $408-418$.

[40]S.M.A. Hosseini *, A. Azimi ;" The inhibition of mild steel corrosion in acidic medium by 1-methyl-3-pyridin2-yl-thiourea"Corros. Sci. 51 (2009) 728-732.

[41]R.M.Issa , M.K.Awad , and F.M.Atlam :" Quantum chemical studies on the inhibition of corrosion of copper surface by substituted uracils" Appl.Surf. Sci. ; 255(2008) 2433.
Structure-Activity Relationship for Oil

[42]G.Gece :" The use of quantum chemical methods in corrosion inhibitor studies" Corro.Sci ; 50 (2008) 2981.

[43]X.Li ,S.Deng, H.Fu and T.Li : "Adsorption and inhibition effect of 6benzylaminopurine on cold rolled steel in $1.0 \mathrm{M} \mathrm{HCl}$ " Electrochimica Acta;54(2009)4089-4098.

[44]Y.Yan,w.h.Li,1.k. and Cal,B.Hou:" Electrochemical and quantum chemical study of purines as corrosion inhibitors for mild steel in $1 \mathrm{M} \mathrm{HCl}$ solution" Electrochimica Acta;53(2009)5953.

[45]O.Kikuch;" Systematic QSAR Procedures with Quantum Chemical Descriptors ", Quant.Struct.Acta 52(1987)179.

[46] W. Li, X. Zhao, F. Liu, J. Deng and B. Hou:;" Investigation on the corrosion inhibitive effect of 2H-pyrazoletriazole derivatives in acidic solution " Materials and Corrosion 60 (2009), 4 , 278-293. 